Working Paper 2010:2

Department of Economics

\title{
Family Job Search, Wage Bargaining, and Optimal Unemployment Insurance
}

Susanne Ek and Bertil Holmlund 
Department of Economics

Working paper 2010:2

Uppsala University

January 2010

P.O. Box 513

ISSN $1653-6975$

SE-751 20 Uppsala

Sweden

Fax: $+{ }_{4} 6184711478$

Family Job Search, Wage Bargaining, and Optimal

UNEMPLOYMENT INSURANCE

Susanne Ek ANd Bertil Holmlund

Papers in the Working Paper Series are published on internet in PDF formats.

Download from http://www.nek.uu.se or from S-WoPEC http://swopec.hhs.se/uunewp/ 


\title{
Family Job Search, Wage Bargaining, and Optimal Unemployment Insurance*
}

\author{
Susanne $\mathrm{Ek}^{\dagger}$ and Bertil Holmlund ${ }^{\ddagger}$
}

This draft: January 11, 2010

\begin{abstract}
The paper develops an equilibrium search and matching model where two-person families as well as singles participate in the labor market. We show that equilibrium entails wage dispersion among equally productive risk-averse workers. Marital status as well as spousal labor market status matter for wage outcomes. In general, employed members of two-person families receive higher wages than employed singles. The model is applied to a welfare analysis of alternative unemployment insurance systems, recognizing the role of spousal employment as a partial substitute for public insurance. The optimal system involves benefit differentiation based on marital status as well as spousal labor market status. Optimal differentiation yields small welfare gains but gives rise to large wage differentials.
\end{abstract}

JEL codes: J31, J64, J65

Keywords: Job search, wage bargaining, wage differentials, unemployment, unemployment insurance

\footnotetext{
${ }^{*}$ We are grateful for useful comments from Per Engström and Philipp Kircher. Thanks also to seminar participants at Uppsala and participants at the IZA workshop on unemployment insurance and flexicurity.

${ }^{\dagger}$ Department of Economics, Uppsala University, Box 513, SE-751 20 Uppsala, Sweden Susanne.Ek@nek.uu.se

¥Department of Economics, Uppsala University, Box 513, SE-751 20 Uppsala, Sweden. Bertil.Holmlund@nek.uu.se
} 


\section{Introduction}

The literature on job search has largely ignored the fact that around every second labor force participant is a member of a multiple-person household. This stands in stark contrast to the literatures on consumption, labor supply and income distributions, where the family perspective is paramount. In this paper we develop an equilibrium search and matching model of the labor market where the family perspective stands in focus. Marital status and the possibility of spousal income sharing generally matter for wage outcomes when individuals are risk averse and wages are determined through bargaining between workers and firms. In fact, our model implies wage differentials among equally productive workers.

"Large" multiple-person families do feature in some realms of equilibrium search and matching theory. A seminal contribution in this genre was offered by Merz (1995) who studied an economy where each household was described as "a very large extended family", where members could perfectly insure each other against fluctuations in labor income associated with transitions between employment and unemployment. This approach has been adopted by others, including Hall and Milgrom (2008) in a recent paper. The "large family" approach has its virtues, but realism is not one of them. Modern industrialized economies are largely based on husband-wife families with at most two adult workers. Transfers across generations may occur so as to achieve some income smoothing but complete smoothing is utterly unrealistic. Empirical work has documented that consumption among U.S. workers falls substantially as unemployment strikes and that the presence of unemployment insurance markedly reduces the drop in consumption (Gruber, 1997). ${ }^{1}$

The model we propose appears to be new in the literature. The economy we study is populated by two types of households, singles and couples. All household members participate in the labor force and are either employed or unemployed. Wages are set in a decentralized fashion through worker-

\footnotetext{
${ }^{1}$ Gruber (1997) argues that the empirical results "decisively reject the notion that there are complete private consumption markets for unemployment spells..."
} 
firm bargaining. An unemployed worker in a two-person family can benefit from some consumption insurance through a working spouse, an option that is not available for singles. This will generally lead to different bargaining outcomes for singles and couples since the outside options differ. Wages will also differ between ex ante identical members of different two-person families depending on whether the family has one or two employed members.

Our model naturally lends itself to an analysis of optimal unemployment insurance (UI). The availability of some private income smoothing should arguably be recognized when designing the optimal UI system. One issue is whether benefits should be based on individual or family income. When wages differ across workers, the question of optimal replacement rates also becomes relevant. For example, does the optimal system involve flat rate or earnings-related benefits? This issue is related to the debate over "Bismarckian" versus "Beveridgean" social insurance schemes; see for example Casamatta et al (2000) and Goerke (2000).

The paper proceeds by a brief discussion of related literature. Section 3 presents the model. We show that marital status as well as spousal labor market status matter for wage outcomes. Section 4 provides a welfare analysis of alternative unemployment insurance systems, recognizing the role of spousal employment as a partial substitute for public insurance. Section 5 concludes the paper.

\section{Related Literature}

The paper relates to the literature on wage dispersion in frictional labor markets. The empirical literature has documented that wages vary among workers with observationally similar characteristics, a fact that has inspired modeling of frictional wage dispersion. This literature, mainly in the search and matching tradition, has derived conditions under which wage differentials can arise even for workers who are ex ante identical, i.e., identical before labor force status is determined. The wage-posting model of Burdett and 
Mortensen (1998) is a leading example. ${ }^{2}$ In their model, job seekers are ex ante identical but may end up with different reservation wages as they have the option to engage in on-job-search and job-to-job mobility. This reservation wage heterogeneity creates a tradeoff for firms: high-wage firms are able to attract and retain more workers than low-wage firms are, but the rent per worker that high-wage firms can extract is relatively low. Our paper shows that wage differentials can arise among workers with identical ex ante characteristics, such as between workers in two different two-person families where a partner is unemployed in one case and employed in the other. Spousal employment outcomes matter for bargained wages when risk-averse spouses practice income sharing.

Another related literature is concerned with the "added worker effect" and spousal labor supply as insurance. The paper by Burdett and Mortensen (1978) on labor supply under uncertainty studies job search by couples using a standard partial equilibrium search framework. When one family member becomes unemployed, part of the income loss can be offset by increased spousal labor supply. ${ }^{3}$ As shown by Cullen and Gruber (2000), this supply response may be substantially weakened by unemployment insurance. Our paper assumes exogenous search intensity and spousal job loss leads to wage adjustment but no change in search effort. However, an extension of the basic model to incorporate endogenous search effort would include mechanisms akin to the added worker effect. An unemployed family member's search effort would respond to labor market outcomes of the spouse since those outcomes influence overall family income.

The paper also relates to the literature on optimal unemployment insurance design. This literature has focused on issues such as the case for benefit variation over the spell of unemployment and the interaction between UI and

\footnotetext{
${ }^{2}$ See Rogerson et al (2005) for a survey of search models of the labor market.

${ }^{3}$ Garcia-Perez and Rendon (2004) present an empirical model of family job search and consumption where spousal interactions are modeled in detail, partly along the lines of Burdett and Mortensen (1978). The recent paper by Guler et al (2008) studies theoretically the joint job-search and location problem of a two-person household.
} 
active labor market policy. ${ }^{4}$ Most papers have considered economies without wage dispersion. However, when wages differ across workers, a new issue arises about the optimal differentiation of benefits across workers with different past or prospective wages. One policy, in the spirit of Beveridge, involves flat rate benefits. A "Bismarckian" alternative involves instead earningsrelated benefits, thus implying higher benefit levels for workers with high past or potential wages. We also consider benefit differentiation based on marital status and spousal labor market status. The model is used to provide welfare assessments of alternative UI systems.

Finally, it is worth noting that numerous empirical studies have documented the existence of a male marriage wage premium: married males earn substantially higher wages than unmarried ones (see e.g. Korenman and Neumark, 1991). Our paper suggests that a marriage premium can arise as a result of wage bargaining when married persons can effectively wield stronger bargaining power as a result of intra-family income pooling. However, the model as it stands does not explain why marriage appears to yield a wage premium for men but not for women.

\section{The Model}

\subsection{The Labor Market}

The economy is populated by households who are either singles or families consisting of couples. For concreteness, we will sometimes refer to members of two-person families as husbands and wives. The individuals have identical preferences and are equally productive in all firms. All individuals are labor force participants and the total labor force is fixed and normalized to unity. There are no transitions between marital states so the fraction of singles in the labor force is constant. Workers are either employed or unemployed and have infinite time horizons. Time is continuous and an employed worker is separated from the job at an exogenous Poisson rate $\phi$. Upon entering

\footnotetext{
${ }^{4}$ See Fredriksson and Holmlund (2006) for a survey.
} 
unemployment, the worker is immediately eligible for (time invariant) UI benefits.

There are three relevant labor market states for a two-person family: (i) both spouses employed; (ii) both spouses unemployed; and (iii) one spouse employed and one spouse unemployed. A family where both spouses are (un)employed will be referred to as fully (un)employed; a family with mixed employment status is referred to as partially (un)employed.

All unemployed workers are engaged in job search with an exogenous intensity. There is no on-the-job search. The matching function that relates the aggregate flow of hires to the number of vacancies $(v)$ and the number of unemployed $(u)$ exhibits constant returns to scale: $M=m(v, u)$. Let $\theta \equiv v / u$ denote labor market tightness. The probability per unit time that an individual finds a job is $\alpha=m(v, u) / u=\alpha(\theta)$. Also, $\alpha(\theta)=m(v, u) / u=$ $m(\theta, 1)$ and hence $\alpha^{\prime}(\theta)>0$; the tighter the labor market, the easier to find a job. Firms fill vacancies at the rate $q(\theta)=m(v, u) / v=m(1,1 / \theta)$, and thus $q^{\prime}(\theta)<0$; the tighter the labor market, the more difficult to fill a vacancy. By constant returns to scale, $\alpha(\theta)=\theta q(\theta)$ holds.

The steady state flow equilibrium relationship for this economy can be summarized by an unemployment relationship of the form

$$
u=\frac{\phi}{\phi+\alpha(\theta)}
$$

This is the aggregate unemployment rate in the economy as well as the unemployment rate pertaining to singles and couples, respectively. Absent differences in search efforts or separation rates across groups, there will be no group differences in unemployment rates (or, equivalently, the fraction of time spent as unemployed). The probability that any given individual is unemployed is thus given by $u$ and the employment probability is $1-u$. The spouses' probabilities of being (un)employed are independent of each other. The probability that a couple is fully employed is thus $(1-u)^{2}$, the probability of a mixed employment status is $2 u(1-u)$, and the probability that both spouses are unemployed is $u^{2}$. 


\subsection{Households}

The individual's instantaneous utility function is increasing in consumption. Individuals do not have access to a capital market so consumption equals income at each instant. Couples practice income sharing at the 50/50 rate so each spouse receives half of the total family income. The level of consumption varies across individuals in two dimensions, viz. labor market status (employed vs. unemployed) and marital status (single vs. couple). For employed singles, average household income is simply the wage, $w_{0}$; for unemployed singles, income is given by unemployment benefits, $b$. For couples, there are three possibilities depending on labor market status. If both spouses are unemployed, average income is $(b+b) / 2=b$; if one spouse is employed and the other is unemployed, average income is $\left(w_{1}+b\right) / 2$, where $w_{1}$ is the wage received by the working spouse; if both spouses are employed, average income per member is given by $\left(w_{2}+w_{2}\right) / 2=w_{2}$, where $w_{2}$ is the wage received by members of a fully employed family. The logic of the wage notation for couples is that subscript 1 is used if one person is employed and subscript 2 if two persons are employed.

Wages may differ with respect to marital status and may also differ depending on whether workers belong to fully or partially employed families. As will be shown, such wage differentials may arise under Nash bargaining over wages. For now we proceed under the assumption that benefits are of the flat rate variety: all unemployed individuals thus receive the same benefit level, $b$, when unemployed. This may not be an optimal UI system, an issue to which we will return.

Utility functions are taken to be isoelastic of the form

$$
v(c)=\frac{c^{1-\rho}-1}{1-\rho}
$$

where $c$ denotes consumption (income) and $\rho$ is the degree of relative risk aversion, $\rho \geq 0$. Linear utility obtains when $\rho=0$ and logarithmic utility when $\rho \rightarrow 1$. The notation for the instantaneous utilities in the various states are as follows. Unemployed singles as well as unemployed individuals in wholly unemployed families: $v(b)$; employed singles: $v\left(w_{0}\right)$; members of 
partially employed families: $v\left(w_{1} ; b\right)$ or just $v\left(w_{1}\right)$ (recall that average income in this state is $\left.\left(w_{1}+b\right) / 2\right)$; and members of wholly employed families: $v\left(w_{2}\right) .^{5}$

Consider the intertemporal objective functions for singles (superscript $s$ ) and couples (superscript $c$ ). Let $U^{s}$ denote the expected discounted present value of utility for a single unemployed worker and let $N^{s}$ denote the corresponding value if the person is employed. The value functions can be written as

$$
\begin{aligned}
& r U^{s}=v(b)+\alpha\left(N^{s}-U^{s}\right) \\
& r N^{s}=v\left(w_{0}\right)+\phi\left(U^{s}-N^{s}\right)
\end{aligned}
$$

where $\alpha=\alpha(\theta)$ and $r$ is the subjective rate of time preference. These two equations imply a present value differential between employment and unemployment of the form

$$
N^{s}-U^{s}=\frac{v\left(w_{0}\right)-v(b)}{\alpha+\phi}
$$

when evaluated at $r=0$.

For individuals living in two-person families, the value functions are slightly non-standard since income sharing implies interdependence between the spousal valuations: labor market events directly affecting the husband affect the wife's consumption, and vice versa. Let $U^{c}$ denote the expected discounted present value of utility for each family member if both spouses are unemployed, $E^{c}$ the value associated with mixed employment status, and $N^{c}$ the corresponding value if both spouses are employed. There are three

\footnotetext{
${ }^{5}$ Multiple person households can benefit from economies of scale in consumption, a possibility that is recognized in studies of income distribution among households of different sizes. The literature has suggested several alternative "equivalence scales" so as to allow welfare comparisons across different family sizes (see Atkinson et al, 1995). The square root scale is one example. This scale divides household income by the square root of household size. To get individual size-adjusted income for a two-person family we would thus divide family income by $\sqrt{2} \approx 1.4$ rather than by 2 . It can be shown that such an adjustment does not affect equilibrium outcomes or optimal policies in our model.
} 
relevant value functions for a member of a two-person household:

$$
\begin{aligned}
r U^{c} & =v(b)+2 \alpha\left(E^{c}-U^{c}\right) \\
r E^{c} & =v\left(w_{1} ; b\right)+\alpha\left(N^{c}-E^{c}\right)+\phi\left(U^{c}-E^{c}\right) \\
r N^{c} & =v\left(w_{2}\right)+2 \phi\left(E^{c}-N^{c}\right)
\end{aligned}
$$

Consider the case with two family members unemployed. The husband (as well as the wife) receives $b$ as instantaneous unemployment compensation. He finds a job at the rate $\alpha$, thereby entering partial employment and its associated present value $E^{c}$. The capital gain from such a transition is $E^{c}-$ $U^{c}$. His wife also finds a job at the rate $\alpha$ and her transition brings her, as well as her husband, to partial employment with present value $E^{c}$. The probability that both spouses simultaneously receive job offers is negligible in a short time interval. Consider next the case with mixed employment status (partial unemployment). An unemployed husband finds a job at the rate $\alpha$, a transition that is associated with present value $N^{c}$. His employed wife runs the risk $\phi$ of losing her job, thereby moving the family into full time unemployment with present value $U^{c}$. Finally, the fully employed household includes spouses who both earn $w_{2}$. The husband as well as the wife runs the risk $\phi$ of being laid off, thus entering partial unemployment. The probability that both spouses will simultaneously be laid off is negligible in a short time interval.

Evaluated at $r=0$, the present value differences can be written as:

$$
\begin{aligned}
E^{c}-U^{c} & =\left(\frac{1}{\alpha+\phi}\right) \frac{(\alpha+2 \phi)\left[v\left(w_{1}\right)-v(b)\right]+\alpha\left[v\left(w_{2}\right)-v\left(w_{1}\right)\right]}{2(\alpha+\phi)} \\
N^{c}-E^{c} & =\left(\frac{1}{\alpha+\phi}\right) \frac{(2 \alpha+\phi)\left[v\left(w_{2}\right)-v\left(w_{1}\right)\right]+\phi\left[v\left(w_{1}\right)-v(b)\right]}{2(\alpha+\phi)}
\end{aligned}
$$

Consider eq. (8). The present value difference between partial and full unemployment is the discounted value of a weighted average of utility differences between partial and full unemployment, $v\left(w_{1}\right)-v(b)$, and between full and partial employment, $v\left(w_{2}\right)-v\left(w_{1}\right)$. The weights depend on the job finding rate, $\alpha$, and the job destruction rate, $\phi$. Note that the value difference 
$E^{c}-U^{c}$ is more heavily affected by the immediate income difference between partial and full unemployment, $v\left(w_{1}\right)-v(b)$, than by the prospective future income difference between full and partial employment, $v\left(w_{2}\right)-v\left(w_{1}\right)$. Analogous interpretations hold for eq. (9).

\subsection{Firms}

Firms operate under constant returns to labor, an assumption that allow us to treat the job as the stand in for the firm (Pissarides, 2000). Workers and jobs are randomly matched, implying that the firm with some probability will encounter a worker from a single-person household, a worker from a wholly unemployed family, or a worker from a partially employed family. These three categories of workers may earn different wages. Let $y$ denote the constant level of labor productivity, uniform across firms and workers, $J_{0}$ the present discounted value of job occupied by a single-household worker , $J_{1}$ the value of a job occupied by a worker from a partially employed family, and $J_{2}$ the value of a job matched to a member of a wholly employed family. The value of opening a vacancy is denoted $V$. The value functions pertaining to occupied jobs are written as:

$$
\begin{aligned}
& r J_{0}=y-w_{0}+\phi\left(V-J_{0}\right) \\
& r J_{1}=y-w_{1}+\phi\left(V-J_{1}\right)+\alpha\left(J_{2}-J_{1}\right) \\
& r J_{2}=y-w_{2}+\phi\left(V-J_{2}\right)+\phi\left(J_{1}-J_{2}\right)
\end{aligned}
$$

where $r$ here stands for the rate of interest, by assumption equal to the individual's subjective rate of time preference.

Eq. (10) is the standard job valuation function with one type of worker and no wage differences. The firm's instantaneous surplus is given by $y-w_{0}$ and the job is destroyed at the exogenous rate $\phi$. Eqs. (11) and (12) are non-standard and capture worker interdependencies in two-person families. Consider eq. (11). A job occupied by a worker from a partially employed family is destroyed at the rate $\phi$, just as a job occupied by a worker from a single-person household. However, there is also a possibility that the worker's 
unemployed spouse will find a job, an event that triggers a wage renegotiation. The spouse encounters and accepts job offers at the rate $\alpha$, causing a change in the present value of the job equal to $J_{2}-J_{1}$. The third value function, eq. (12), states that the value of a job occupied by a worker from a wholly employed family runs two types of risks. There is a risk that the job itself is destroyed, an event that occurs at the rate $\phi$. There is also a risk that the employed worker's spouse is hit by a job destruction in her firm; this event also strikes at the rate $\phi$. This spousal job loss leads to wage renegotiation and therefore a change in the value of the job.

The solutions of the value functions, evaluated at $r=0$ and $V=0$ (free entry) are obtained as

$$
\begin{array}{ll}
J_{0} & =\frac{1}{\phi}\left(y-w_{0}\right) \\
J_{1} & =\frac{1}{\phi}\left[y-\left(\lambda w_{1}+(1-\lambda) w_{2}\right)\right] ; \quad \lambda \in(0,1) \\
J_{2} & =\frac{1}{\phi}\left[y-\left(\delta w_{1}+(1-\delta) w_{2}\right)\right] ; \quad \delta \in(0,1)
\end{array}
$$

where $\lambda \equiv 2 \phi /(\alpha+2 \phi), \delta \equiv \phi /(\alpha+2 \phi)$, and $J_{2}-J_{1}=\left(w_{1}-w_{2}\right) /(\alpha+2 \phi)$. The value of an occupied job is given as the discounted present value of the surplus. Note that the average wage cost pertaining to employed couples is given as a weighted average of the wages for members of partially and wholly employed families, $w_{1}$ and $w_{2}$.

It remains to consider the value of opening a vacancy. The flow value of keeping a vacancy is denoted $k$ and the firm meets unemployed job seekers at the rate $q(\theta)$. The probability that a job seeker is single is given by the fraction of singles in the population, $\gamma$; the probability of finding a married seeker is thus $1-\gamma$. Upon encountering a married job seeker, the probability that he or she belongs to a wholly unemployed family is $u$ whereas the probability of coming from partial employment is $1-u$. The value function takes the form

$$
r V=-k+q(\theta)\left[\gamma J_{0}+(1-\gamma)\left(u J_{1}+(1-u) J_{2}\right)-V\right]
$$


which can be rewritten as

$$
y-\left\{\gamma w_{0}+(1-\gamma)\left[u w_{1}+(1-u) w_{2}\right]\right\}=\frac{k \phi}{q(\theta)}
$$

where free entry, $V=0$, is imposed along with eqs. (13), (14) and (15). Note also that $u=u(\theta)$ as given by (1). The left-hand side of (17) is the excess of the marginal product of labor over expected wage costs. In equilibrium, this surplus equals the expected capitalized value of the vacancy cost, i.e., $k \phi / q(\theta)$. Since $u^{\prime}(\theta)<0$ and $q^{\prime}(\theta)<0$, the job creation condition provides a relationship between tightness and each of the three wage rates. A sufficient (but not necessary) condition for $\partial \theta / \partial w_{j}<0, j=0,1,2$, is $w_{2} \geq w_{1}$.

\subsection{Wage Bargaining}

Wages are determined by decentralized worker-firm Nash bargaining. As usual in these models, the relevant threat point for the single worker is the value of unemployment, $U^{s}$. Let $\beta \in(0,1)$ denote the worker's bargaining power. The relevant Nash product for singles is then

$$
\Omega\left(w_{0}\right) \equiv\left(N^{s}-U^{s}\right)^{\beta}\left(J_{0}-V\right)^{1-\beta}
$$

and the first-order condition evaluated at $V=0$ is

$$
(1-\beta)\left(N^{s}-U^{s}\right)=\beta J_{0} \frac{\partial v\left(w_{0}\right)}{\partial w_{0}}
$$

For workers in two-person families, there are two cases to consider. A worker from a partially employed family has continued unemployment as the relevant threat point, i.e., $U^{c}$. The relevant Nash product is thus

$$
\Omega\left(w_{1}\right) \equiv\left(E^{c}-U^{c}\right)^{\beta}\left(J_{1}-V\right)^{1-\beta}
$$

with the first-order condition at $V=0$ as

$$
(1-\beta)\left(E^{c}-U^{c}\right)=\beta J_{1} \frac{\partial v\left(w_{1}\right)}{\partial w_{1}}
$$

The threat point for a worker from a wholly employed family is different since income sharing cushions the income loss associated with failure to strike 
a bargain. We assume that each spouse acts on her own, taking the partner's wage, $\tilde{w}_{2}$, as given. Instantaneous income associated with disagreement is given by $\left(b+w_{1}\right) / 2$ rather than $b$ and the relevant threat point is thus given by $E^{c}$. The Nash product is then

$$
\Omega\left(w_{2}\right) \equiv\left(N^{c}-E^{c}\right)^{\beta}\left(J_{2}-V\right)^{1-\beta}
$$

and the corresponding first-order condition at $V=0$ is

$$
(1-\beta)\left(N^{c}-E^{c}\right)=\beta J_{2} \frac{\partial v\left(w_{2} ; \tilde{w}_{2}\right)}{\partial w_{2}}
$$

The magnitude of a worker's instantaneous marginal utility of a wage increase, $\partial v\left(w_{j}\right) / \partial w_{j}, j=0,1,2$, plays a crucial role for wage outcomes. For a single worker, we have $\partial v\left(w_{0}\right) / \partial w_{0}=1$ for linear utility and $\partial v\left(w_{0}\right) / \partial w_{0}=$ $1 / w_{0}$ for $\log$ utility. For a worker in a partially employed family we get $\partial v\left(w_{1}\right) / \partial w_{1}=1 / 2$ for linear and $\partial v\left(w_{1}\right) / \partial w_{1}=1 /\left(b+w_{1}\right)$ for log utility. Finally, for workers in wholly employed families we have $\partial v\left(w_{2}\right) / \partial w_{2}=1 / 2$ for linear and $\partial v\left(w_{2}\right) / \partial w_{2}=1 / 2 w_{2}$ for log utility when evaluated at a symmetric equilibrium with $w_{2}=\tilde{w}_{2}$. It is clear from the first-order conditions that an increase in the marginal utility of a wage hike is analogous to an increase in the worker's relative bargaining power, i.e., $\beta /(1-\beta)$.

\subsection{Equilibrium}

All the ingredients of the model are now in place. There are 11 endogenous variables: $u, \theta, N^{s}-U^{s}, E^{c}-U^{c}, N^{c}-E^{c}, J_{0}, J_{1}, J_{2}, w_{0}, w_{1}, w_{2}$. The relevant equations are (1), (4), (8), (9), (13), (14), (15), (17) - (20). To solve the model it is useful to focus on the job creation condition along with the three wage bargaining equations. The latter three equations, stated in (18), (19) and (20), can after relevant substitutions be written as 


$$
\begin{aligned}
\frac{1}{\alpha+\phi}\left[v\left(w_{0}\right)-v(b)\right] & =\hat{\beta}\left(\frac{y-w_{0}}{\phi}\right) \frac{\partial v\left(w_{0}\right)}{\partial w_{0}} \\
\frac{\alpha v\left(w_{2}\right)+2 \phi v\left(w_{1}\right)-(\alpha+2 \phi) v(b)}{2(\alpha+\phi)^{2}} & =\frac{\hat{\beta}}{\phi}\left[y-\lambda w_{1}-(1-\lambda) w_{2}\right] \frac{\partial v\left(w_{1}\right)}{\partial w_{1}} \\
\frac{(\phi+2 \alpha) v\left(w_{2}\right)-2 \alpha v\left(w_{1}\right)-\phi v(b)}{2(\alpha+\phi)^{2}} & =\frac{\hat{\beta}}{\phi}\left[y-\delta w_{1}-(1-\delta) w_{2}\right] \frac{\partial v\left(w_{2} ; \tilde{w}_{2}\right)}{\partial w_{2}}
\end{aligned}
$$

where $\hat{\beta}=\beta /(1-\beta)$ measures the worker's relative bargaining power, $\lambda=2 \phi /(\alpha+2 \phi), \delta=\lambda / 2$ and $\alpha=\alpha(\theta)$. Eqs. (21) - (23), imposing a symmetric equilibrium with $w_{2}=\tilde{w}_{2}$ along with the job creation condition (17), determine $\theta, w_{0}, w_{1}$ and $w_{2}$. Unemployment is obtained from (1) once tightness is determined. The numerical versions of the model that we have considered always deliver unique equilibria. ${ }^{6}$

\subsection{Wage Differentials}

Consider wage outcomes for the three types of workers, viz. a worker from a single-person household, a worker from a partially employed family, and a worker from a wholly employed family. It is useful to begin with linear utility functions in which case we obtain closed form solutions for the wage equations, i.e., bargained wages as functions of (endogenous) tightness and the exogenous variables. The first-order conditions imply wage equations of the form

$$
w_{j}=\frac{\beta[\alpha(\theta)+\phi]}{\phi+\alpha(\theta) \beta} y+\frac{(1-\beta) \phi}{\phi+\alpha(\theta) \beta} b, \quad j=0,1,2
$$

Bargained wages are given as weighted averages of productivity and benefits. The weight on productivity is increasing in tightness which implies that wages are increasing in tightness since $y>b$. It is immediately obvious that wages are independent of marital status and spousal labor market status. Hence:

\footnotetext{
${ }^{6}$ With isoelastic utility and risk aversion $(\rho>0), b>0$ is required.
} 
Proposition 1 Equilibrium in the family search model entails no wage dispersion among equally productive risk-neutral workers.

To get some intuition for the role of risk aversion, consider a special case of our model where one spouse (the "breadwinner") is permanently employed earning the wage $\omega$, whereas the other spouse (the "secondary worker") is moving back and forth between employment and unemployment. The breadwinner's wage effectively functions as a state-independent income subsidy to the secondary worker in the family. The instantaneous utility difference between employment and unemployment for this family would take the form

$$
D \equiv \frac{1}{1-\rho}\left[(w+\omega)^{1-\rho}-(b+\omega)^{1-\rho}\right]
$$

where $\partial D / \partial \omega \leq 0$ as $\rho \geq 0$ and $\omega>b$. With log utility we have $D=$ $\ln (w+\omega)-\ln (b+\omega)$ and $\partial D / \partial \omega=(w+\omega)^{-1}-(b+\omega)^{-1}<0$. A higher breadwinner wage reduces the utility difference between employment and unemployment when the utility function is strictly concave. This implies a decrease in the surplus from agreement and thus stronger incentives for a wage increase.

However, the impact of the subsidy on the negotiated wage depends also on the marginal utility of a wage hike, i.e., $\partial v(w) / \partial w=(w+\omega)^{-\rho}$. This marginal utility is decreasing in $\omega$ for $\rho>0$ so a higher breadwinner wage entails incentives for wage moderation via this mechanism; there is obviously zero impact if $\rho=0$. With log utility, the wage moderation effect is dominated by the wage push effect, i.e., $\partial w / \partial \omega>0 .^{7}$ The bottom line is that state-independent income supplements matter for wage outcomes when individuals are risk averse but they do not matter under risk neutrality.

Wage outcomes in our model are driven by the worker's surplus from agreement as well as by the marginal utility to the worker of a wage hike,

\footnotetext{
${ }^{7}$ Too verify this claim, consider the first-order condition
}

$$
\frac{1}{\alpha+\phi}[\ln (w+\omega)-\ln (b+\omega)]=\hat{\beta}\left(\frac{y-w}{\phi}\right) \frac{1}{w+\omega}
$$

and differentiate with respect to $w$ and $\omega$, holding $\alpha(\theta)$ constant. 
i.e., $\partial v\left(w_{j}\right) / \partial w_{j}, j=0,1,2$. Consider $\log$ utility and assume for a moment that wage equality prevails, i.e., $w_{0}=w_{1}=w_{2}=w$. We would then have $\partial v\left(w_{0}\right) / \partial w_{0}=1 / w$ for singles, $\partial v\left(w_{1}\right) / \partial w_{1}=1 /(b+w)$ for partially employed families, and $\partial v\left(w_{2}\right) / \partial w_{2}=1 / 2 w$ for wholly employed families. Hence the following inequalities would apply (for $b<w$ ): $\partial v\left(w_{0}\right) / \partial w_{0}>$ $\partial v\left(w_{1}\right) / \partial w_{1}>\partial v\left(w_{2}\right) / \partial w_{2}$. The marginal utility of a wage hike would be highest for a worker from a single-person household. Moreover, the marginal utility of a wage hike would be higher for partially employed families than from wholly employed families. All else equal, these inequalities would suggest $w_{0}>w_{1}>w_{2}$.

All else are, of course, not equal. The worker's surplus from a wage agreement varies by marital status and spousal labor market status. Two-person households can benefit from partial income insurance via spousal transfers and such transfers will presumably reduce the utility difference between employment and unemployment and thereby increase wage pressure. It appears difficult to give precise general characterizations of wage differentials but it turns out that overall wage equality is incompatible with equilibrium. To prove this claim, assume $w_{0}=w_{1}=w_{2}=w$ and check whether an equlibrium exists under these assumptions. Use (21) and (22) to substitute out $y-w$ and define $R \equiv b / w$ as the replacement rate. The resulting expression boils down to

$$
2[\ln (1+R)-\ln 2]=\ln R
$$

which has no meaningful solution since $L H S>R H S$ for $R \in(0,1)$. We have $L H S \in(-2 \ln 2,0)$ and $R H S \in(-\infty, 0)$ for $R \in(0,1)$. Hence:

Proposition 2 Equilibrium in the family search model entails wage dispersion among equally productive risk-averse workers.

To examine spousal wage differences we proceed analogously. Assume $w_{1}=w_{2}=w$ and use (22) and (23) to obtain

$$
2\left(\frac{u}{1-u}\right)=\frac{\ln R}{\ln (1+R)-\ln 2}-\frac{4}{1+R}
$$


where we have invoked $\phi / \alpha(\theta)=u /(1-u)$. A meaningful solution to this equation requires an implausibly low replacement rate. The RHS of (27) must be positive but a postive sign obtains only for $R<0.1373$. Consistency with realistic unemployment rates in a range between 5 and 10 percent requires even lower replacement rates. Wage equality between spouses is thus a highly unlikely outcome.

We have used a calibrated version of the model to examine wage and employment outcomes when individuals are risk averse; see Appendix 1. The baseline calibration involves a log utility function and a benefit/output ratio of one half, $b / y=0.5$, which implies replacement rates slightly greater than 50 percent. (With flat rate benefits and wage differentials, replacement rates will of course vary across groups.) Output per worker is normalized to unity, $y=1$. The baseline features an unemployment rate of 6 percent. Table 1 shows how wages and unemployment vary by relative risk aversion. Wages are ranked as $w_{1}>w_{2}>w_{0}$. Thus employed family members receive higher wages than employed singles and workers in partially employed families earn more than workers in wholly employed families. The magnitudes of the wage differentials increase as risk aversion increases. With relatively high risk aversion $(\rho=2)$, workers in partially employed two-person families earn 4.5 percent higher wages than working singles. Two-person families can provide partial income insurance to its members, a fact that contributes to higher wage pressure by reducing the utility surplus of employment relative to unemployment.

Table 1. The impact of risk aversion.

\begin{tabular}{|c|c|c|c|c|}
\hline & $\rho=0$ & $\rho=1 / 2$ & $\rho=1$ & $\rho=2$ \\
\hline$w_{0}$ & 0.969 & 0.956 & 0.962 & 0.954 \\
$w_{1}$ & 0.969 & 0.980 & 0.988 & 0.998 \\
$w_{2}$ & 0.969 & 0.968 & 0.968 & 0.967 \\
\hline $\ln \left(w_{1} / w_{0}\right)$ & 0 & 0.015 & 0.027 & 0.045 \\
$\ln \left(w_{2} / w_{0}\right)$ & 0 & 0.003 & 0.006 & 0.014 \\
$\ln \left(w_{2} / w_{1}\right)$ & 0 & -0.012 & -0.021 & -0.031 \\
$u$ & 0.066 & 0.063 & 0.060 & 0.054 \\
\hline \hline
\end{tabular}


A noteworthy feature of our model is that the shares of singles and couples in the population matter for unemployment and wage differentials. Singles have no access to spousal income insurance, a fact that suggests that unemployment would fall if the share of singles $(\gamma)$ increases. Indeed, this is what the numerical analysis confirms. An increase in $\gamma$ from 0.3 to 0.7 leads to a decline in unemployment from 6.1 to 5.9 percent.

\subsection{The Impact of Benefits}

To understand how benefits affect wage outcomes, consider the three bargaining equations as given by (21), (22) and (23). As usual and as is clear from (21), a uniform rise in benefits reduces the single worker's surplus from agreement and this tends to lead to a wage increase. From (23) it follows that the same mechanism operates for workers in wholly employed families. The incentives are however less clear for workers in partially employed families. Examine eq. (22) and note that a benefit increase has several effects. First, there is the conventional effect operating via $v(b)$ which reduces the worker's surplus from agreement and thus triggers an increase in wage pressure. Second, there are two effects operating via $v\left(w_{1} ; b\right):(i)$ a rise in $b$ is akin to an in-work subsidy which increases average income and thus $v\left(w_{1} ; b\right)$ for the partially employed family, an effect which tends to offset part of the conventional impact; $(i i)$ a rise in $b$ also reduces the marginal utility of a wage increase via $\partial v\left(w_{1} ; b\right) / \partial w_{1}$, a fact that encourages wage moderation. All in all, there are no reasons to expect that uniform benefit increases should have uniform wage effects. It is conceivable that benefit increases actually will encourage wage moderation among workers in partially employed families. This conjecture is confirmed by the numerical exercises reported in Table 2: $w_{1}$ decreases when $b$ increases whereas $w_{0}$ and $w_{2}$ increases. $^{8}$

\footnotetext{
${ }^{8}$ The experiments in Table 2 and Table 3 ignore the government's budget restriction, but the broad features of the results carry over to the case when benefits are fully financed by taxes on wages.
} 
Table 2. The impact of uniform benefit changes.

\begin{tabular}{|c|c|c|c|}
\hline & $b / y=0.4$ & $b / y=0.5$ & $b / y=0.6$ \\
\hline$w_{0}$ & 0.956 & 0.962 & 0.968 \\
$w_{1}$ & 0.990 & 0.988 & 0.986 \\
$w_{2}$ & 0.964 & 0.968 & 0.971 \\
\hline $\ln \left(w_{1} / w_{0}\right)$ & 0.035 & 0.027 & 0.018 \\
$\ln \left(w_{2} / w_{0}\right)$ & 0.009 & 0.006 & 0.004 \\
$\ln \left(w_{2} / w_{1}\right)$ & -0.026 & -0.021 & -0.015 \\
$u$ & 0.053 & 0.060 & 0.069 \\
\hline \hline
\end{tabular}

For reasons discussed above, the impact of selective benefit changes are likely to be different from the results shown in Table 2 . Let $b_{1}$ denote the benefit level for an unemployed individual in partially unemployed families (one unemployed person) and $b_{2}$ the benefit level for wholly unemployed couples (two unemployed persons). The value functions are slightly modified when benefits are differentiated; see Appendix 2. Table 3 presents some numerical comparative statics on selective benefit changes based on our calibrated model. When $b_{1}$ is varied, benefits for singles and wholly unemployed couples are fixed at the baseline value, $b_{0}=b_{2}=0.5$. When $b_{2}$ is varied, the other benefit levels are analogously fixed. It is clear that an increase in $b_{1}$ leads to strong wage moderation among workers in partially employed families, reflecting the fact that $b_{1}$ is analogous to an in-work subsidy. However, an increase in $b_{2}$ increases wage pressure among those workers. ${ }^{9}$

\footnotetext{
${ }^{9}$ We note that $y=1<w_{1}$ holds in some cases. $J_{1}>0$ still holds; what matters for the value of an occupied job is the average wage cost relative to productivity as given by eq. (14).
} 
Table 3. The impact of selective benefit changes.

\begin{tabular}{|c|c|c||c|c|}
\hline & $b_{1} / y=0.4$ & $b_{1} / y=0.6$ & $b_{2} / y=0.4$ & $b_{2} / y=0.6$ \\
\hline$w_{0}$ & 0.963 & 0.962 & 0.963 & 0.961 \\
$w_{1}$ & 1.046 & 0.931 & 0.927 & 1.043 \\
$w_{2}$ & 0.962 & 0.973 & 0.967 & 0.968 \\
\hline $\ln \left(w_{1} / w_{0}\right)$ & 0.083 & -0.032 & -0.038 & 0.082 \\
$\ln \left(w_{2} / w_{0}\right)$ & 0.0002 & 0.012 & 0.004 & 0.008 \\
$\ln \left(w_{2} / w_{1}\right)$ & -0.083 & 0.045 & 0.042 & -0.075 \\
$u$ & 0.059 & 0.061 & 0.058 & 0.062 \\
\hline \hline
\end{tabular}

We proceed by applying our model to an analysis of optimal unemployment insurance. When wages differ among workers, issues concerning the optimal structure of benefits become interesting. Should higher wages also motivate higher unemployment benefits?

\section{Optimal Unemployment Insurance}

\subsection{Alternative UI Schemes}

Unemployment insurance schemes differ markedly across countries. One alternative, often referred to as Beveridgean, involves flat rate benefits, i.e., identical benefit levels for all unemployed individuals. Another system, known as Bismarckian, entails earnings-related benefits and thus higher benefit levels for individuals with higher pre-unemployment earnings. Existing schemes typically differ from the polar types in various ways. One prevalent scheme has borrowed features from both Beveridge and Bismarck and involve a fixed replacement rate up to an earnings threshold and a constant benefit level for earnings above this threshold. The UI schemes also differ with regard to the treatment of family income and individual income as the basis for benefit levels.

Our model can be employed to shed light on the welfare aspects of some of these issues. We have so far mainly focused on flat rate benefits but we will now also consider alternatives where benefit levels differ depending on 
previous earnings. One alternative is the Bismarckian one, i.e., a scheme with constant replacement rates. Another alternative involves optimal differentiation of benefit levels. Benefit differentiation may be based on marital status as well as spousal labor market status. An analysis of optimal UI design also requires explicit treatment of taxes needed to finance the benefits.

Notations and definitions are as follows. Flat rate benefits are denoted $b$ (as before). The benefit level for singles who are unemployed is denoted $b_{0}$; the benefit level for unemployed individuals in partially (un)employed families is denoted $b_{1}$; and the benefit level for individuals in wholly unemployed families is denoted $b_{2}$. The Bismarckian scheme is then defined as

$$
R=\frac{b_{0}}{w_{0}}=\frac{b_{1}}{w_{2}}=\frac{b_{2}}{w_{1}}
$$

where $R$ is the common replacement rate. The logic of our definition for couples is as follows. The immediate unemployment risk facing an individual in a wholly employed family with the wage $w_{2}$ is partial unemployment associated with benefit level $b_{1}$; the fraction replaced income is thus $b_{1} / w_{2}$. The immediate unemployment risk facing an employed individual in a partially employed family with the wage $w_{1}$ is the risk of entering the state of being wholly unemployed and then receive $b_{2}$; the replacement rate is $b_{2} / w_{1}$.

We also need to specify the social welfare function and the mode of benefit financing. The social welfare function is taken to be utilitarian. To simplify the analysis and to allow comparisons of steady states without considering adjustment paths, we let the discount rate approach zero and obtain the objective function as a weighted average of individual per-period expected utilities:

$$
\begin{aligned}
\Lambda= & \gamma\left[u v\left(b_{0}\right)+(1-u) v\left(w_{0}\right)\right]+ \\
& (1-\gamma)\left[(1-u)^{2} v\left(w_{2}\right)+u^{2} v\left(b_{2}\right)\right]+ \\
& (1-\gamma)\left[2 u(1-u) v\left(w_{1} ; b_{1}\right)\right]
\end{aligned}
$$

where we have used the fact the spouses' probabilities of being (un)employed are independent of each other. The probability that any given individual is unemployed is $u$ and the employment probability is $1-u$. The probability 
that a couple is fully employed is $(1-u)^{2}$; the probability that both spouses are unemployed is $u^{2}$; and the probability of a mixed employment status is $2 u(1-u)$.

We assume that benefits are financed by a proportional wage tax on firms. The free entry condition thus takes the form

$$
y-\left\{\gamma w_{0}+(1-\gamma)\left[u w_{1}+(1-u) w_{2}\right]\right\}(1+t)=\frac{k \phi}{q(\theta)}
$$

where $t$ is the wage tax. Tax revenues are

$$
T=t\left\{\gamma(1-u) w_{0}+(1-\gamma)\left[u(1-u) w_{1}+(1-u)^{2} w_{2}\right]\right\}
$$

and government expenditure on benefits is given by

$$
B=\gamma u b_{0}+(1-\gamma)\left[u(1-u) b_{1}+u^{2} b_{2}\right]
$$

We compare four policies. The benchmark case is optimal choice of flat rate benefits subject to the market equilibrium relationships and the government's budget restriction, i.e., $T=B$. The second case involves optimal choice of three benefit levels $\left(b_{0}, b_{1}, b_{2}\right)$ but subject to a replacement rate restriction of the form given by (28). The third case entails benefit differentiation based on marital status but without recognizing spousal labor market status. Singles thus receive $b_{0}$ whereas unemployed couples receive $b_{1}=b_{2}=b^{c}$. The fourth case involves optimal choice of three benefit levels $\left(b_{0}, b_{1}, b_{2}\right)$, thus recognizing marital status as well as spousal labor market status and with no replacement rate restriction imposed. Appendix 3 shows how the bargaining equations are modified when wage taxes are introduced.

\subsection{Numerical Results}

The results are displayed in Table 4 for log utility; the results for higher risk aversion $(\rho=2)$ are broadly similar. The welfare effect of a specific UI regime is measured relative to the flat rate benchmark. It is expressed as the equivalent of a consumption tax that equalizes welfare across policy regimes. Let $\Lambda^{U}$ represent welfare associated with the benchmark and $\Lambda^{A}$ 
welfare associated with an alternative policy. The measure of the welfare gain of policy $A$ relative to policy $U$ is given by the value of the tax rate $\tau$ that solves $\Lambda^{A}[(1-\tau) w ; \cdot]=\Lambda^{U}$. With logarithmic utility functions we have $\Delta \Lambda \equiv \Lambda^{A}-\Lambda^{U}=-\ln (1-\tau) \approx \tau$. We also show welfare gains separately for singles $\left(\Delta \Lambda^{s}\right)$ and couples $\left(\Delta \Lambda^{c}\right)$, where

$$
\begin{aligned}
& \Lambda^{s}=u v(b)+(1-u) v\left(w_{0}\right) \\
& \Lambda^{c}=(1-u)^{2} v\left(w_{2}\right)+u^{2} v\left(b_{2}\right)+2 u(1-u) v\left(w_{1} ; b_{1}\right)
\end{aligned}
$$

and $\Delta \Lambda=\left(\Delta \Lambda^{s}+\Delta \Lambda^{c}\right) / 2$.

The optimal flat benefit level implies a replacement rate close to 50 percent. A replacement rate restriction leads to a slight decrease in welfare compared to flat rate benefits (column 2). Benefit differentiation with respect to marital status (column 3) implies that singles should receive higher benefits than couples: the optimal system involves a replacement rate close to 60 percent for singles and 33 percent for couples. Since singles do not have access to partial income insurance, it is to be expected that they should receive higher benefits than couples. Differentiation with respect to marital status also entails a substantial welfare gain for singles amounting to over 2 percent of consumption. However, there is also a welfare loss for couples of almost the same magnitude so the overall welfare gain relative to flat rate benefits is negligible.

We finally examine optimal differentiation by marital status as well as spousal labor market status (column 4). The optimal benefit levels vary substantially and the implied wage differentials are also large. Benefits for partially unemployed families $\left(b_{1}\right)$ are more than five times larger than the benefits for wholly unemployed families $\left(b_{2}\right)$. Recall that an increase in $b_{1}$ is akin to an in-work subsidy and leads to wage moderation rather than increased wage pressure. Indeed, there is a huge decline in $w_{1}$ accompanying the rise in $b_{1}$. This wage decline contributes to sharply increasing wage differences between workers from families with and without employed spouses. The increase in $b_{1}$ and fall in $w_{1}$ imply that overall consumption among partially employed families, $\left(b+w_{1}\right) / 2$, decreases only marginally with optimal differentiation relative to flat rate benefits. All in all, optimal differentiation 
with respect to both marital status and labor market status has large effects on wage differentials but small effects on overall welfare.

Table 4. Welfare comparisons of alternative UI schemes, log utility.

\begin{tabular}{|c|c|c|c|c|}
\hline & $\begin{array}{r}\text { Flat rate } \\
\text { benefits }\end{array}$ & $\begin{array}{l}\text { Constant } \\
\text { replacement rate }\end{array}$ & $\begin{array}{c}\text { Differentiation } \\
\text { by marital status }\end{array}$ & $\begin{array}{c}\text { Optimal } \\
\text { differentiation }\end{array}$ \\
\hline & (1) & $(2)$ & (3) & (4) \\
\hline$b$ & 0.464 & & & \\
\hline$R$ & & 0.494 & & \\
\hline$b_{0}$ & & 0.460 & 0.561 & 0.582 \\
\hline$b_{1}$ & & 0.478 & 0.311 & 0.881 \\
\hline$b_{2}$ & & 0.464 & 0.311 & 0.151 \\
\hline$\frac{b_{1}+w_{1}}{2}$ & 0.711 & 0.709 & 0.632 & 0.6053 \\
\hline $\ln \left(w_{1} / w_{0}\right)$ & 0.029 & 0.038 & 0.012 & -0.785 \\
\hline $\ln \left(w_{2} / w_{0}\right)$ & 0.007 & 0.007 & -0.016 & 0.011 \\
\hline $\ln \left(w_{2} / w_{1}\right)$ & -0.022 & -0.031 & -0.028 & 0.796 \\
\hline$b / w_{0}$ & 0.498 & & & \\
\hline$b / w_{1}$ & 0.484 & & & \\
\hline$b / w_{2}$ & 0.495 & & & \\
\hline$b_{0} / w_{0}$ & & 0.494 & 0.594 & 0.626 \\
\hline$b_{2} / w_{1}$ & & 0.494 & 0.326 & 0.356 \\
\hline$b_{1} / w_{2}$ & & 0.494 & 0.335 & 0.937 \\
\hline$u$ & 0.059 & 0.059 & 0.058 & 0.057 \\
\hline$t$ & 0.031 & 0.031 & 0.028 & 0.047 \\
\hline$\Delta \Lambda^{s}(\%)$ & & -0.10 & 2.37 & 1.20 \\
\hline$\Delta \Lambda^{c}(\%)$ & & 0.08 & -2.22 & -1.01 \\
\hline$\Delta \Lambda(\%)$ & & -0.01 & 0.08 & 0.09 \\
\hline
\end{tabular}




\section{The Insurance Value of the Family}

Singles have no access to family income sharing and would be willing to pay something in order to have access to a family as an insurance institution. How much would they be willing to pay? We follow the approach above and compare expected utilities for singles and couples, $\Lambda^{s}$ and $\Lambda^{c}$, where employment and wage outcomes are evaluated at the utilitarian planner's solution. The difference $\Delta^{c, s} \equiv \Lambda^{c}-\Lambda^{s}$ is a measure of the welfare gain associated with being member of a two-person family (ignoring non-pecuniary benefits). For log utility and flat rate benefits (i.e. column 1, Table 3), this gain amounts to 1.4 percent; that is, singles would be willing to pay 1.4 percent of their consumption in order to switch family status. The gains are of the same order of magnitude for the other UI schemes. The welfare of being in a two-person family is substantially larger if we also take economies of scale into account. Using square-root scale we divide all family income by $\sqrt{2}$ instead of two. The welfare gain associated with being member of a family is then 36 percent: singles would thus be willing to pay 36 percent of their consumption to switch family status.

\section{Concluding Remarks}

We have developed a model of family job search with individual wage bargaining and examined the implications for equilibrium wage differentials and optimal unemployment insurance. Equilibrium wage differentials arise among risk-averse individuals who are $e x$ ante identical. In general, there is a wage premium for workers in two-person households compared to singles when the UI system involves flat rate benefits or constant replacement rates. The wage differentials are however sensitive to benefit differentiations based on marital status and spousal labor market status. The optimal UI system entails very high benefits for unemployed spouses in partially employed families and very low wages for the working spouses in such families.

Several extensions of the model are conceptually straightforward. For example, it would be possible to introduce endogenous search effort, an ex- 
tension that probably will predict unemployment differences between singles and couples. Our current version of the model with exogenous search effort is effectively imposing identical search efforts across groups, an assumption implying that unemployment rates are independent of marital status.

We have assumed income sharing in the family at the 50/50 rate, equivalent to assuming equal within-family bargaining power for the spouses. It is likely that allowing for gender differences in within-family bargaining power will lead to gender differences in labor market outcomes. The model as it stands is silent about gender wage differentials and it cannot explain the empirical finding that there is a marriage premium for males but not for females.

The family institution provides some protection against income losses and the optimal UI design should arguably take this feature into account. However, our numerical analysis of alternative UI systems gives little support for non-standard alternatives to flat rate benefits. It remains to be seen whether the results still hold when allowing for endogenous search effort as another margin whereby benefits affect wages and unemployment.

Finally, it is noteworthy that so little of empirical work on search and unemployment has taken the family perspective seriously. It would be surprising if this omission were of no relevance for understanding labor market outcomes for family members.

\section{References}

Atkinson, A, L Rainwater and T Smeeding (1995), Income Distribution in OECD Countries, OECD Social Policy Studies, No 18, Paris.

Burdett, K and D Mortensen (1978), Labor Supply under Uncertainty, in R Ehrenberg (ed), Research in Labor Economics. vol 2, JAI Press.

Burdett, K and D Mortensen (1998), Wage Differentials, Employer Size, and Unemployment, International Economic Review 39, 257-273. 
Casamatta, G, H Cremer and P Pestieau (2000), Political Sustainability and the Design of Social Insurance, Journal of Public Economics 75, 341-364.

Cullen, J B and J Gruber (2000), Does Unemployment Insurance Crowd Out Spousal Labor Supply?, Journal of Labor Economics 18, 546-572.

Fredriksson. P and B Holmlund (2006), Improving Incentives in Unemployment Insurance: A Review of Recent Research, Journal of Economic Surveys 20, 357-386.

Garcia-Perez J I and S Rendon (2004), Family Job Search and Consumption, paper presented at the 2004 Meeting of the Society for Economic Dynamics.

Goerke, L (2000), Bismarck versus Beveridge: Flat-Rate and EarningsRelated Unemployment Insurance in a General Efficiency Wage Framework, FinanzArchiv 57, 243-260.

Guler, B, F Guvenen and G Violante (2008), Joint-Search Theory: New Opportunities and New Frictions, manuscript.

Gruber, J (1997), The Consumption Smoothing Benefits of Unemployment Insurance, American Economic Review 87, 192-205.

Hall, R and P Milgrom (2008), The Limited Influence of Unemployment on the Wage Bargain, American Economic Review 98, 1653-1674.

Korenman, S and D Neumark (1991), Does Marriage Really Make Men More Productive?, Journal of Human Resources 26, 282-307.

Merz, M (1995), Search in the Labor Market and the Real Business Cycle, Journal of Monetary Economics 36, 269-300.

Pissarides, C (2000), Equilibrium Unemployment Theory, MIT Press.

Rogerson, R, R Shimer and R Wright (2005), Search-Theoretic Models of the Labor Market, Journal of Economic Literature, vol 43, 959-988. 
APPENDIX 1

\section{A Numerical Model}

Assume that preferences are given by a logarithmic utility function. The time period is taken to be a quarter and the quarterly job destruction rate is set to 7 percent: $\phi=0.07$. The rate of interest (equal to the rate of time preference) is set to zero. The matching function is Cobb Douglas, $M=a v^{\eta} u^{1-\eta}$, where $\eta=0.5$ is assumed (roughly consistent with most empirical studies). Productivity is normalized to unity: $y=1$. Flat rate benefits are fixed at 50 percent of productivity: $b=0.5$. The fraction of singles, $\gamma$, is set to $0.5 .{ }^{10}$ The matching parameter, $a$, and the vacancy cost, $k$, are chosen so as to obtain 6 percent unemployment and a reasonably realistic relationship between the expected duration of vacancies, $1 / q(\theta)$, and the expected duration of unemployment, $1 / \alpha(\theta)$. (The duration of vacancies is empirically much shorter than the the duration of unemployment.) We set $a=2$ and chose a value of $k$ that gives 6 percent unemployment: $k=1.8$. Table A1 presents some output implied by these parameter choices.

Table A1. A numerical model, log utility.

\begin{tabular}{|c|c|}
\hline & \\
$\theta$ & 0.299 \\
\hline$u$ & 0.060 \\
\hline Vacancy duration (weeks) & 3.55 \\
\hline Unemployment duration (weeks) & 11.88 \\
\hline$w_{0}$ & 0.962 \\
\hline$w_{1}$ & 0.988 \\
\hline$w_{2}$ & 0.968 \\
\hline $\ln \left(w_{1} / w_{0}\right)$ & 0.027 \\
$\ln \left(w_{2} / w_{0}\right)$ & 0.006 \\
$\ln \left(w_{2} / w_{1}\right)$ & -0.021 \\
\hline \hline
\end{tabular}

\footnotetext{
${ }^{10}$ According to the US Census, 50 percent of the US population $(15+)$ are married with spouse present in 2008 .
} 


\section{APPENDIX 2}

Value Functions with Differentiated Benefits

Consider the intertemporal objective functions when benefits may differ across marital status and labor market states (wholly unemployed versus partially unemployed). For singles we have

$$
\begin{aligned}
& r U^{s}=v\left(b_{0}\right)+\alpha\left(N^{s}-U^{s}\right) \\
& r N^{s}=v\left(w_{0}\right)+\phi\left(U^{s}-N^{s}\right)
\end{aligned}
$$

and thus

$$
N^{s}-U^{s}=\frac{v\left(w_{0}\right)-v\left(b_{0}\right)}{\alpha+\phi}
$$

when evaluated at $r=0$. For couples we have

$$
\begin{aligned}
& r U^{c}=v\left(b_{2}\right)+2 \alpha\left(E^{c}-U^{c}\right) \\
& r E^{c}=v\left(w_{1} ; b_{1}\right)+\alpha\left(N^{c}-E^{c}\right)+\phi\left(U^{c}-E^{c}\right) \\
& r N^{c}=v\left(w_{2}\right)+2 \phi\left(E^{c}-N^{c}\right)
\end{aligned}
$$

The present value differences, evaluated at $r=0$, can be written as

$$
\begin{aligned}
E^{c}-U^{c} & =\frac{(\alpha+2 \phi)\left[v\left(w_{1} ; b_{1}\right)-v\left(b_{2}\right)\right]+\alpha\left[v\left(w_{2}\right)-v\left(w_{1} ; b_{1}\right)\right]}{2(\alpha+\phi)^{2}} \\
N^{c}-E^{c} & =\frac{(2 \alpha+\phi)\left[v\left(w_{2}\right)-v\left(w_{1}\right)\right]+\phi\left[v\left(w_{1} ; b_{1}\right)-v\left(b_{2}\right)\right]}{2(\alpha+\phi)^{2}}
\end{aligned}
$$




\section{APPENDIX 3}

\section{Wage Bargaining with Taxes}

Payroll taxes are levied on firms in order to finance UI benefits. This implies value functions for firms of the form

$$
\begin{array}{ll}
J_{0} & =\frac{1}{\phi}\left(y-\omega_{0}\right) \\
J_{1} & =\frac{1}{\phi}\left[y-\left(\lambda \omega_{1}+(1-\lambda) \omega_{2}\right)\right] ; \quad \lambda \in(0,1) \\
J_{2}=\frac{1}{\phi}\left[y-\left(\delta \omega_{1}+(1-\delta) \omega_{2}\right)\right] ; \quad & \delta \in(0,1)
\end{array}
$$

where $\omega_{j}=w_{j}(1+t)$ is the wage cost inclusive of the tax rate $t$. Nash bargaining then implies first-order conditions of the form

$$
\begin{aligned}
(1-\beta)\left(N^{s}-U^{s}\right) & =\frac{\beta J_{0}}{w_{0}(1+t)} \\
(1-\beta)\left(E^{c}-U^{c}\right) & =\frac{\beta J_{1}}{\left(w_{1}+b_{1}\right)(1+t)} \\
(1-\beta)\left(N^{c}-E^{c}\right) & =\frac{\beta J_{2}}{w_{2}(1+t)}
\end{aligned}
$$


WORKING PAPERS*

Editor: Nils Gottfries

2008:8 Erik Glans, The effect of changes in the replacement rate on partial retirement in Sweden. 30pp.

2008:9 Erik Glans, Retirement patterns during the Swedish pension reform. 44pp.

2008:10 Stefan Eriksson and Jonas Lageström, The Labor Market Consequences of Gender Differences in Job Search. 16pp.

2008:11 Ranjula Bali Swain and Fan Yang Wallentin, Economic or Non-Economic Factors - What Empowers Women?. 34pp.

2008:12 Matz Dahlberg, Heléne Lundqvist and Eva Mörk, Intergovernmental Grants and Bureaucratic Power. 34pp.

2008:13 Matz Dahlberg, Kajsa Johansson and Eva Mörk, On mandatory activation of welfare receivers. $39 \mathrm{pp}$.

2008:14 Magnus Gustavsson, A Longitudinal Analysis of Within-Education-Group Earnings Inequality. 26pp.

2008:15 Henrique S. Basso, Delegation, Time Inconsistency and Sustainable Equilibrium. 24pp.

2008:16 Sören Blomquist and Håkan Selin, Hourly Wage Rate and Taxable Labor Income Responsiveness to Changes in Marginal Tax Rates. 31 pp.

2008:17 Jie Chen and Aiyong Zhu, The relationship between housing investment and economic growth in China : A panel analysis using quarterly provincial data. 26pp.

2009:1 Per Engström, Patrik Hesselius and Bertil Holmlund, Vacancy Referrals, Job Search, and the Duration of Unemployment: A Randomized Experiment. $25 \mathrm{pp}$.

2009:2 Chuan-Zhong Li and Gunnar Isacsson, Valuing urban accessibility and air quality in Sweden: A regional welfare analysis. 24pp.

2009:3 Luca Micheletto, Optimal nonlinear redistributive taxation and public good provision in an economy with Veblen effects. $26 \mathrm{pp}$.

2009:4 Håkan Selin, The Rise in Female Employment and the Role of Tax Incentives. An Empirical Analysis of the Swedish Individual Tax Reform of $1971.38 \mathrm{pp}$.

\footnotetext{
* A list of papers in this series from earlier years will be sent on request by the department.
} 
2009:5 Lars M. Johansson and Jan Pettersson, Tied Aid, Trade-Facilitating Aid or Trade-Diverting Aid? 47pp.

2009:6 Håkan Selin, Marginal tax rates and tax-favoured pension savings of the selfemployed Evidence from Sweden. 32pp.

2009:7 Tobias Lindhe and Jan Södersten, Dividend taxation, share repurchases and the equity trap. $27 \mathrm{pp}$.

2009:8 Che-Yuan Liang, Nonparametric Structural Estimation of Labor Supply in the Presence of Censoring. 48pp.

2009:9 Bertil Holmlund, Incentives in Business and Academia. 12pp.

2009:10 Jakob Winstrand, The Effects of a Refinery on Property Values - The Case of Sweden. 27pp.

2009:11 Ranjula Bali Swain and Adel Varghese. The Impact of Skill Development and Human Capital Training on Self Help Groups. 28pp.

2009:12 Mikael Elinder. Correcting Mistakes: Cognitive Dissonance and Political Attitudes in Sweden and the United States. 25 pp.

2009:13 Sören Blomquist, Vidar Christiansen and Luca Micheletto: Public Provision of Private Goods and Nondistortionary Marginal Tax Rates: Some further Results. 41pp.

2009:14 Mattias Nordin: The effect of information on voting behavior. 34pp.

2009:15 Anders Klevmarken, Olle Grünewald and Henrik Allansson A new consumer price index that incorporates housing. $27 \mathrm{pp}$.

2009:16 Heléne L. Nilsson How Local are Local Governments? Heterogeneous Effects of Intergovernmental Grants. 41pp.

2009:17 Olof Åslund, Per-Anders Edin, Peter Fredriksson and Hans Grönqvist: Peers, neighborhoods and immigrant student achievement - evidence from a placement policy. $27 \mathrm{pp}$.

2009:18 Yunus Aksoy, Henrique S. Basso and Javier Coto-Martinez: Lending Relationships and Monetary Policy. 42 pp.

2009:19 Johan Söderberg: Non-uniform staggered prices and output persistence. 38 pp.

2010:1 Jonathan Gemus: College Achievement and Earnings. 43 pp.

See also working papers published by the Office of Labour Market Policy Evaluation http://www.ifau.se/ 